\title{
ESTUDO DOS PARÂMETROS DOS RESÍDUOS SÓLIDOS DOMICILIARES DECORRENTES DA IMPLANTAÇÃO DA COLETA SELETIVA NO MUNICÍPIO DE ASSIS-SP.
}

Autor Principal

Inajara Fiusa de Barros Ramos

Orientador

Dr. Fernando Frei

Instituição

Universidade Estadual Júlio de Mesquita Filho - UNESP/Assis

E-mail de contato

inafiusa@bol.com.br

Palavras-chave:

coleta seletiva, reciclagem, resíduos sólidos.

\section{INTRODUÇÃO}

Com uma população de cerca 6,7 bilhões de habitantes (U.S. Census Bureau, 2008), o planeta Terra passa por uma fase crítica no que diz respeito à degradação do meio ambiente. A deterioração da natureza e a escassez dos recursos naturais são fatos presentes e claramente visíveis, sobretudo, nas grandes cidades. (CORSON, 1996). O crescente volume de resíduos sólidos, resultado do desenvolvimento tecnológico e dos elevados índices de consumo, é, em parte, responsável por essa agressão. (GARDNER, 2004; LEME e JÓIA, 2006).

Resíduos sólidos são os resíduos sólidos e semi-sólidos que derivam de atividades industriais, hospitalares, comerciais, agrícolas, serviços de varrição e atividades domésticas (ABNT, 1987). O Brasil produz atualmente 150 mil toneladas desses resíduos 
por dia, o que representa, em média, 750 gramas por pessoa; entretanto, menos de $5 \%$ desse total é reciclado (AGÊNCIA BRASIL, 2007).

No país, cabe às prefeituras municipais planejar o serviço de coleta, a definição das formas de tratamento e a disposição final de todo resíduo produzido. Para minimizar os problemas advindos da produção de lixo, o poder público tem investido em diversos programas, geralmente em parceria com catadores de lixo e usinas de reciclagem e compostagem, obtendo alguns resultados positivos e com estes, incentivado a reciclagem no Brasil.

Reciclagem e compostagem são processos que podem ser caracterizados pelo respeito ao meio ambiente, conscientização e participação da população e pela proposição de políticas de desenvolvimento sustentável (LEME e JOIA, 2006), uma vez que contribuem para a redução do volume de lixo produzido, prolongam a vida útil dos aterros sanitários, evitam a proliferação de aterros clandestinos, diminuem a poluição da água, solo e ar, bem como geram renda e emprego, economizam energia e matérias-primas e, além da promoção das melhorias nas condições higiênico-sanitárias e de saúde da população (CORSON, 1996).

Contudo, políticas públicas para questões relativas aos resíduos sólidos domiciliares e para temas como saneamento básico e ambiental ainda são escassas e insuficientes, apresentando-se como um dos desafios da sociedade atual, visto sua estreita relação com a saúde humana (LEME e JÓIA, 2006).

Como mencionado anteriormente, a associação entre Prefeituras e catadores tem se transformado em uma parceria eficaz para a coleta de resíduos sólidos recicláveis. No caso do município de Assis (SP), a prefeitura local estabeleceu seu primeiro convênio com a Cooperativa dos Catadores de Materiais Recicláveis de Assis (COOCASSIS) em agosto de 2003, ocorrendo, desde então, o programa de coleta seletiva solidária - o qual abrange cerca de $60 \%$ do município (Secretaria de Planejamento, Obras e Serviços PMA, 2008). Tais associações geram uma série de benefícios como a possibilidade de maiores rendimentos para os cooperados, significativo decréscimo na taxa de materiais destinados ao aterro, o que diminui o impacto ambiental causado pela excessiva produção atual de lixo, além da inclusão social via reconhecimento do indivíduo que, 
antes marginalizado, agora tem seu trabalho de catador reconhecido, através da implementação formal da coleta seletiva de resíduos.

Pelo exposto, entende-se que o conhecimento de características quantitativas e qualitativas dos resíduos sólidos produzidos pela população, é fundamental para que cada município possa adotar medidas que contribuam para a implementação e acompanhamento de políticas públicas capazes de gerar formas equilibradas de consumo que sejam harmônicas às necessidades sociais e ambientais, capazes de atender as condições básicas de qualidade de vida (GARDNER, 2004), bem como produzir estudos que possam auxiliar e sustentar a implantação de projetos que visem minimizar os impactos produzidos pelos resíduos sólidos domiciliares (LEME e JÓIA, 2006).

\section{OBJETIVO GERAL}

Este estudo tem como objetivos analisar a eficiência do Parque de Reciclagem e Compostagem de Resíduos Sólidos "José Santilli Sobrinho" e verificar a contribuição da coleta seletiva do lixo domiciliar na cidade de Assis - SP em dois momentos distintos, antes $^{1}$ e após sua implantação, bem como avaliar o impacto social da constituição da própria cooperativa junto aos cooperados.

\section{OBJETIVOS ESPECÍFICOS}

3.2.1. Quantificação diária do total de lixo domiciliar destinado ao Parque e de rejeito, destinada ao aterro sanitário.

3.2.2. Quantificação diária dos resíduos sólidos avaliados como materiais recicláveis.

3.2.3. Tipologia dos materiais recicláveis separados na usina.

3.2.4. Quantificação do material putrescível destinado à compostagem.

\section{METODOLOGIA}

1. Qualidade dos Materiais Reciclados Separados na Usina de Reciclagem e Compostagem de Lixo da Prefeitura Municipal de Assis-Sp. Monografia de conclusão de curso. Faculdade de Ciências e Letras de Assis - UNESP. Gil, M.L.; BONGIOVANNI, S; FREI, F.2003.Assis.SP. 
O levantamento de dados foi realizado junto ao Parque de Reciclagem e Compostagem de Resíduos Sólidos "José Santilli Sobrinho", localizado no Assis (SP), durante os meses de agosto, setembro, outubro, novembro e dezembro de 2008 e no mês de janeiro de 2009, totalizando 26 semanas.

Para a obtenção dos dados relativos ao peso do lixo domiciliar urbano referente à coleta seletiva, foram utilizadas as estatísticas da Cooperativa de Catadores de Materiais Recicláveis de Assis (COOCASSIS). No que tange aos resíduos domiciliares urbanos coletados pela Prefeitura Municipal de Assis (SP), os dados foram obtidos por meio da aferição do peso líquido de cada caminhão utilizado no decorrer de 13 dias.

Os resíduos foram classificados em "resíduos comercializados", os demais, encaminhados ao aterro municipal em "rejeitos". Os dados referentes aos "rejeitos" foram obtidos mediante a aferição do peso liquido dos caminhões que se destinavam ao aterro durante duas semanas. Por outro lado, para ampliar a amostra desta categoria, foi realizada a estimativa dos rejeitos mediante a subtração do total de resíduos comercializados, em relação ao total de lixo domiciliar produzido no município durante as 26 semanas de estudo.

Durante o processo de triagem, os materiais destinados à comercialização foram separados conforme a classificação:

- Papel, subdividido em papel, papelão e, embalagens de "Tetra Pak";

- Plástico, subdividido em "pet" e plástico, propriamente dito;

- Metal/Sucata, subdividido em aço, alumínio I, alumínio II, antimônio, cobre, metal;

- Vidro, que não apresenta subdivisões;

Os dados foram analisados por técnicas estatísticas descritivas (medidas, tabelas e gráficos), testes inferenciais (nível de $5 \%$ ) para comparação de variáveis nos dois períodos em análise e Intervalo de Confiança para a estimativa da percentagem média de resíduos comercializados e de rejeitos (95\% de nível de confiança).

\section{RESULTADOS}


Verificou-se que o município de Assis-SP produz diariamente uma média de 47 toneladas de lixo, das quais aproximadamente $11 \%$ são reaproveitadas e destinadas à reciclagem. Conseqüentemente, as taxas de rejeito diminuíram de $95,8 \%$ para $89 \%$ o que representa uma redução de 155 toneladas de lixo mensalmente depositadas no aterro e um acréscimo de 95 toneladas de materiais recicláveis destinados à comercialização devido a implantação da coleta seletiva no município.

Como o processo de compostagem ainda não foi implantado, o restante do material, composto principalmente por matéria orgânica, não passa por nenhum tipo de tratamento e é depositado diretamente no aterro sanitário local.

Comparando-se a produção per capita de lixo produzido diariamente nos anos de 2003 (em média, 510 gramas) e 2008/09 (em média, 500 gramas), nota-se que houve um decréscimo de cerca de 10 gramas.

Quando analisadas as percentagens de materiais destinados à comercialização, é observado um aumento, de $4,2 \%$ para $11 \%$, correspondente respectivamente aos anos 2003 e 2008/09. Conseqüentemente, as taxas de rejeito diminuíram de 95,8\% para 89\%. O valor médio de materiais reciclados obtido pela triagem do lixo domiciliar urbano nas 24 semanas aferidas foi igual a 25,2 toneladas com intervalo de confiança de 95\% [20,3 a $30,2]$. Por outro lado, do total do material obtido junto à coleta seletiva, $100 \%$ é comercializado pela cooperativa.

Quanto à comparação tipológica dos materiais destinados a comercialização, houve um aumento significativo na categoria "Papéis", que abrange papéis coloridos e brancos, papelão, jornais, revistas e outros tipos. Em 2003 essa categoria representava 21,8\% do total de material destinado à comercialização e em 2008/09 representou 52,1\%. Notou-se também um grande decréscimo na categoria "Metal/Sucata", que representa em 2008/09 $7,4 \%$ dos materiais destinados a comercialização contra os $33,9 \%$ que representava em 2003. Já as categorias "Plástico" e "Vidro" oscilaram pouco, representando, respectivamente, $25,4 \%$ e $18,9 \%$ em 2003 e $27,5 \%$ e $13 \%$ em 2008/09.

\section{CONSIDERAÇÕES FINAIS}


No município de Assis (SP), o programa de coletiva seletiva apresentou em 2008/2009 uma abrangência geográfica da ordem de $60 \%$. A ampliação da cobertura traria um incremento ao programa e um aumento na percentagem de materiais coletados e destinados à reciclagem. Paralelamente à atuação da COOCASSIS há a necessidade da implantação de políticas de conscientização populacional, práticas relacionadas à educação ambiental, bem como de técnicas de tratamento dos resíduos orgânicos, ainda inexistentes no município. Os dados apresentados demonstram que a separação está ocorrendo com qualidade visto que a comercialização dos materiais obtidos no programa é de $100 \%$.

Pelo exposto, o modelo adotado na cidade de Assis (SP), a parceria entre a Prefeitura Municipal e a Cooperativa COCASSIS, apresenta pontos favoráveis, pois proporcionou a organização dos catadores de lixo trazendo diversos benefícios para os mesmos, bem como a redução de rejeitos destinados ao aterro municipal. Torna-se necessário, porém, a ampliação das regiões atendidas pela coleta seletiva, uma possível maior adesão dos moradores à coleta, a inclusão de novos cooperados, o desenvolvimento eficaz do processo de compostagem e campanhas educacionais para maior conscientização da população sobre a questão dos resíduos sólidos.

\section{REFERÊNCIAS}

ABNT, ASSOCIAÇÃO BRASILEIRA DE NORMAS TÉCNICAS. NBR 10.00 4- Resíduos sólidos: classificação. São Paulo. 63 p.1987.

Agência Brasil. Proposta de política nacional busca agregar valor aos resíduos sólidos. Disponível em <URL:http://www.agenciabrasil.gov.br/noticias/2007/09/22/materia.200709-2.5801431228/view> [2008 fev 2]

Corson, W. H. Manual global de Ecologia - o que você pode fazer a respeito da crise do meio ambiente. $2^{\mathrm{a}}$ ed. São Paulo: Augustus; 1996.

Gardner G., Assadourian E., Sarin R. O estado do mundo. Worldwatch Institute; 2004

Leme, S. M. \& Jóia, P. R. Caracterização dos resíduos sólidos urbanos domiciliares em Aquidauana-MS. Geografia - v. 15 n.1; jan./jun. 2006. 


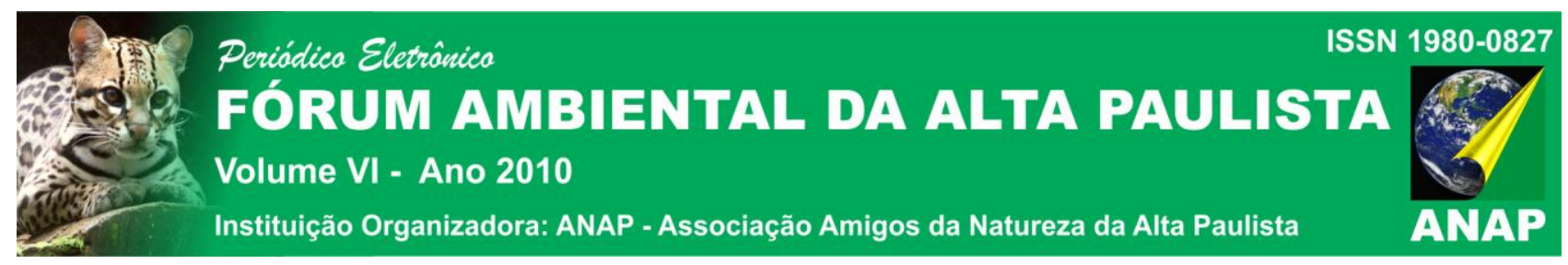

U. S. Census Bureau. Total Midyear Population for the World; 1950-2050. Disponível em http://www.census.gov/ipc/www/idb/worldpop.php. (Acessado em 4/12/2008) 